\title{
A estrutura da representação social de família para idosos residentes em lares intergeracionais
}

\author{
How the social representation of family is structured in elderly residents of \\ intergenerational homes

\section{La estructura de la representación social de familia para ancianos residentes en lares intergeneracionales}

\author{
Doane Martins da SilvaI; Alba Benemérita Alves Vilela ${ }^{I I}$; Denize Cristina de Oliveira ${ }^{I I I}$; Marta dos Reis Alves ${ }^{I V}$
}

\begin{abstract}
RESUMO: O estudo objetiva analisar a estrutura representacional de idosos residentes em lares intergeracionais sobre família. Trata-se de uma pesquisa qualitativa, desenvolvida com o suporte da Teoria das Representações Sociais, na sua perspectiva estrutural com 75 pessoas idosas cadastradas na área de abrangência de uma estratégia saúde da família em um município do Estado da Bahia. Os dados foram coletados através de evocações livres ao termo indutor família, durante o primeiro semestre de 2013 e analisados pelo software EVOC. Observa-se um provável núcleo estruturado a partir dos termos base, união, tudo e companheirismo, ao mesmo tempo em que os elementos periféricos apresentam léxicos como cuidado, amor e respeito, ambos os conjuntos positivos. Conclui-se que a estrutura representacional revela uma forte carga afetiva dos idosos no tocante à família. Palavras-Chave: Família; envelhecimento; idoso; psicologia social.
\end{abstract}

\begin{abstract}
This qualitative study analyzed the structure of representations of family in elderly residents of intergenerational homes, using the structural approach of Social Representations Theory with 75 older adults registered in the Family Health Strategy catchment area of a municipality in Bahia State. Data were collected during the first half of 2013 through free evocation by the inductor term 'family', and analyzed using EVOC software. A probable core was observed, structured from the terms 'base', 'union', 'everything' and 'companionship', while peripheral elements comprised terms such as 'care', 'love' and 'respect'. Both sets were affirmative. It was concluded that the representational structure reveals strong, family-related affective content in older adults. Keywords: Family; aging; older adults; social psychology.

RESUMEN: El estudio pretende analizar la estructura representacional de ancianos residentes en hogares intergeneracionales sobre familia. Se trata de una investigación cualitativa, desarrollada con el soporte de la Teoría de las Representaciones Sociales, en su perspectiva estructural con 75 personas ancianas registradas en el área de alcance una estrategia salud de la familia en un municipio del Estado de Bahia-Brasil. Los datos fueron colectados a través de evocaciones libres al término inductor familia, durante el primer semestre de 2013 y analizados por el software EVOC. Se observa un probable núcleo estructurado de los términos base, unión, todo y compañerismo, al mismo tiempo en que los elementos periféricos presentan léxicos como cuidado, amor y respeto. Se concluye que la estructura representacional revela una fuerte carga afectiva de los ancianos en lo referente a la familia. Palabras Clave: Familia; envejecimiento; anciano; psicología social.
\end{abstract}

\section{INTRODUÇÃO}

Os países em desenvolvimento, dentre eles o Brasil, vêm passando por um processo de transição demográfica que repercute no envelhecimento da população ${ }^{1}$. Estimase que, até 2025, o Brasil será o sexto país no mundo em número de idosos, alcançando o contingente de 30 milhões de indivíduos ${ }^{2}$. Entre 2000 e 2010, a população com 60 anos ou mais cresceu substancialmente, passando de 14,5 milhões para aproximadamente 20,6 milhões, representando $11 \%$ da população brasileira ${ }^{3}$. envelhecimento populacional, associado às modificações econômicas e sociais que acompanham a industrialização e a modernização das sociedades, tem afetado a constituição das famílias brasileiras, pois estas também envelhecem; o que pode ser medido pelo aumento da proporção das famílias nas quais reside um ou mais idoso, seja como chefe do domicílio ou em corresidência com filhos e/ou netos, o que significa uma simultaneidade de várias gerações ${ }^{4}$.

\footnotetext{
'Enfermeira. Mestranda do Programa de Pós-Graduação em Enfermagem e Saúde da Universidade Estadual do Sudoeste da Bahia. Jequié, Bahia, Brasil. E-mail: doane.ef@hotmail.com.

IIEnfermeira. Doutora em Enfermagem. Professora Pleno do Curso de Graduação em Enfermagem da Universidade Estadual do Sudoeste da Bahia. Jequié, Bahia, Brasil. E-mail: albavilela@gmail.com.br

IIIEnfermeira. Doutora em Saúde Pública. Professora Titular do Programa de Pós-Graduação em Enfermagem da Universidade do Estado do Rio de Janeiro. Brasil.E-mail: dcouerj@gmail.com

${ }^{\text {IV }}$ Mestranda do Programa de Pós-Graduação em Enfermagem e Saúde da Universidade Estadual do Sudoeste da Bahia. Jequié, Bahia, Brasil. E-mail: martareisalves@yahoo.com.br
} 
A corresidência tem se tornado uma prática generalizada nos arranjos familiares de idosos, o que pode ocorrer devido ao adiamento da saída dos filhos por questões econômicas, como também pela inserção da pessoa idosa na residência dos filhos em decorrência da necessidade de cuidados ${ }^{4}$, pois verifica-se que, em geral, a corresidência é um arranjo observado para as pessoas idosas que reportam graves condições de saúde e maior dependência funcional $l^{5}$.

Nessa perspectiva, verifica-se que o prolongamento da vida, sobretudo nos países em desenvolvimento, nos quais as políticas públicas para o envelhecimento ainda precisam efetivamente se consolidar, a família permanece como primeiro e fundamental recurso disponível às pessoas idosas. Portanto, a convivência intergeracional com fluxo bidirecional de apoio, recursos e cuidados entre a pessoa idosa e sua família constitui importante estratégia de sobrevivência entre as pessoas idosas.

Neste cenário, apresenta-se como fundamental a compreensão da estrutura das representações que as próprias pessoas idosas construíram sobre família em meio a este novo arranjo familiar, qual seja a corresidência, marcada pela convivência intergeracional.

Destaca-se que estudos que tenham como enfoque o indivíduo idoso são de grande importância, pois tratam de uma realidade complexa que vem acompanhada de grandes transformações em várias esferas, dentre elas, a composição dos arranjos familiares.

Assim, analisar as representações de família para pessoas idosas residentes em lares intergeracionais é relevante, já que em épocas anteriores não houve um contato tão longo e intenso entre as várias gerações de uma mesma família como na atualidade. Ao mesmo tempo, destaca-se que estudos em representação social com a temática família subsidia a construção de conhecimentos acerca dos universos consensuais dos indivíduos envolvidos no processo de viver em família.

A partir das considerações traçadas, definiu-se como objetivo deste estudo analisar a estrutura representacional de idosos residentes em lares intergeracionais sobre família.

\section{Referencial Teórico-Metodológico}

Trata-se de uma pesquisa qualitativa, desenvolvida com o suporte da Teoria das Representações Sociais, na sua perspectiva estrutural ou também chamada de Teoria do Núcleo Central ${ }^{6}$.

Nesse contexto, define-se representação social como processo de uma atividade mental, pela qual um indivíduo ou um grupo recompõe a realidade com a qual ele se defronta e para a qual ele atribui um determinado significado 7 . De acordo com a Teoria do Núcleo Central, a organização de uma representação social apresenta a característica de ser organizada em torno de um núcleo central, constituído por um ou mais elementos que dão significado à representação, bem como fornecem um sentido rígido e não negociável à mesma ${ }^{8}$.

A pesquisa foi desenvolvida junto a pessoas idosas cadastradas na área de abrangência de uma estratégia saúde da família (ESF) na área urbana do município de Jequié - Bahia. A coleta de dados foi realizada com 75 pessoas idosas, cadastradas na ESF, que corresidem em lares intergeracionais (duas ou três gerações), pertencentes à faixa etária de 60 anos ou mais e com grau de cognição suficiente para responder aos instrumentos de coleta de dados, avaliado segundo os escores no Mini Exame do Estado Mental (MEEM), proposto pelo Ministério da Saúde ${ }^{9}$. Os sujeitos foram localizados com intermédio dos Agentes Comunitários de Saúde.

Empregou-se a técnica de evocações livres para a coleta de dados, utilizando-se como termo indutor a palavra família, no transcorrer do primeiro semestre do ano de 2013, por meio de visitas domiciliares. A aplicação da técnica consistiu em solicitar aos idosos que falassem cinco palavras ou expressões que lhes ocorriam imediatamente à cabeça em relação ao termo referido ${ }^{10,11}$ sendo as mesmas imediatamente registradas pelo pesquisador em impresso próprio.

Os vocábulos provenientes da técnica de evocações de palavras foram digitados e agrupados em ordem alfabética, gerando um dicionário que norteou a categorização das evocações, agrupando palavras com significados semelhantes. $O$ produto das evocações foi organizado previamente, constituindo um corpus de análise.

O material foi, então, tratado pelo software EVOC (versão 2003), que possibilita efetuar a organização dos termos produzidos em função da hierarquia subjacente à frequência e à ordem média de evocação (OME) e favorece a construção do quadro de quatro casas. O programa calcula e informa para o conjunto do corpus, a frequência simples de cada palavra evocada, as ordens médias de evocação de cada palavra e a média das ordens médias de evocação ou rang ${ }^{10}$, que neste estudo obedeceu à ordem natural das evocações produzidas pelos sujeitos.

A utilização do programa gerou relatórios que possibilitaram a construção do quadro de quatro casas, proposto por Vergès ${ }^{12}$. Essa técnica, ao combinar dois atributos relacionados às palavras ou às expressões evocadas, que são a frequência e a ordem em que foram evocadas ou hierarquizadas, possibilita a distribuição dos termos produzidos segundo a importância atribuída pelos sujeitos ${ }^{10}$.

O quadro de quatro casas corresponde a quatro quadrantes com quatro conjuntos de termos. No quadrante superior esquerdo ficam situados os termos mais frequentes e mais prontamente evocados e que 
constituem, provavelmente, o núcleo central da representação estudada. No quadrante inferior esquerdo localizam-se os elementos de contraste; o quadrante superior direito denomina-se como primeira periferia e as palavras localizadas no quadrante inferior direito constituem a segunda periferia da representação ${ }^{8}$.

O estudo obedeceu aos pré-requisitos éticos preconizados pela Resolução no 466/2012, do Conselho Nacional de Saúde. Assim, o projeto foi aprovado pelo Comitê de Ética em Pesquisa (CEP) da Universidade do Estadual do Sudoeste da Bahia (UESB), Parecer n $163.351 / 2012$, sendo obtida autorização da Secretaria Municipal de Saúde de Jequié para a realização da pesquisa na USF, além da autorização dos sujeitos, expressa na assinatura do Termo de Consentimento Livre e Esclarecido.

\section{Resultados E Discussão}

A análise do corpus formado pelas evocações dos idosos pesquisados revelou que, em resposta ao termo indutor família, foram evocadas 339 palavras, sendo 278 iguais e 61 diferentes. $O$ rang, ou seja, a média das ordens médias de evocação foi de 2,8, enquanto a frequência média foi de 12 e a mínima, 5. Ver Figura 1.

As informações apresentadas no quadro de quatro casas obedecem aos princípios de frequência de aparecimento e da ordem natural das evocações, permitindo esquematicamente traduzir tais elementos em quadrantes com distintos significados.
Os elementos alocados no quadrante superior esquerdo são possivelmente os elementos pertencentes ao núcleo central, possuem elevada frequência acompanhada de baixa ordem de evocação ${ }^{10}$. Por este motivo são considerados os elementos que podem constituir o núcleo central da representação social de família para pessoas idosas em lares intergeracionais.

Apesar da importância dos elementos do núcleo central na concepção dos sujeitos estudados ${ }^{10}$, é importante salientar que nem tudo que se encontra nesse quadrante pode ser considerado como central, mas o núcleo central está entre eles ${ }^{13}$. Esses elementos caracterizam o que é mais consensual e estável da representação, sendo menos sensível a mudanças em relação ao contexto externo ou das práticas cotidianas dos sujeitos ${ }^{6}$.

Logo, as palavras base, união, tudo e companheirismo aparecem neste quadrante, sendo complementares entre si, direcionando para uma concepção de família como unidade essencial para o processo de viver destes idosos, uma instituição afetiva, expressando a normatividade social sobre a mesma.

Nesse quadrante, destacam-se os vocábulos base, que apresentou a primeira maior frequência e a segunda ordem média de evocação, o que o coloca como o mais importante componente do núcleo central, e o vocábulo tudo, o mais prontamente evocado, expressando uma dimensão avaliativa inespecífica, de completude e inteireza atribuída à família por estes idosos.

A família pode ser considerada a instituição mais importante para a organização humana na so-

\begin{tabular}{|c|c|c|c|c|c|}
\hline \multicolumn{3}{|c|}{$\begin{array}{c}\text { ELEMENTOS CENTRAIS } \\
\text { Frequência média }>=12 / \text { OME }<2,8\end{array}$} & \multicolumn{3}{|c|}{$\begin{array}{l}\text { ELEMENTOS PRIMEIRA PERIFERIA } \\
\text { Frequência média }>=12 \text { / OME }>=2,8\end{array}$} \\
\hline $\begin{array}{l}\text { Base } \\
\text { União } \\
\text { Tudo } \\
\text { Companheirismo }\end{array}$ & $\begin{array}{l}\text { Freq } \\
25 \\
14 \\
13 \\
12\end{array}$ & $\begin{array}{l}\text { Rang } \\
2,32 \\
2,64 \\
1,69 \\
2,50\end{array}$ & $\begin{array}{l}\text { Cuidado } \\
\text { Amor } \\
\text { Felicidade } \\
\text { Respeito } \\
\text { Ajuda }\end{array}$ & $\begin{array}{c}\text { Freq } \\
33 \\
31 \\
26 \\
15 \\
14\end{array}$ & $\begin{array}{c}\text { Rang } \\
3,12 \\
2,87 \\
3,30 \\
3,00 \\
3,42\end{array}$ \\
\hline $\begin{array}{l}\text { ELEMENTOS } \\
\text { Frequência méd }\end{array}$ & CONTI & $\begin{array}{l}\mathrm{TE} \\
<2,8\end{array}$ & $\begin{array}{l}\text { ELEMEN } \\
\text { Frequênci }\end{array}$ & $\begin{array}{l}\text { JNDA } \\
=12 / C\end{array}$ & $\begin{array}{l}\text { FERIA } \\
>=2,8\end{array}$ \\
\hline $\begin{array}{l}\text { Porto seguro } \\
\text { Carinho } \\
\text { Paz } \\
\text { Viver bem } \\
\text { Filhos } \\
\text { Harmonia } \\
\text { Proteção } \\
\text { Benção divina }\end{array}$ & $\begin{array}{l}9 \\
8 \\
7 \\
5 \\
5 \\
5 \\
5 \\
5\end{array}$ & $\begin{array}{l}2,66 \\
2,62 \\
2,42 \\
2,40 \\
2,20 \\
2,20 \\
2,20 \\
2,00\end{array}$ & $\begin{array}{l}\text { Apoio } \\
\text { Dedicação } \\
\text { Atenção } \\
\text { Satisfação } \\
\text { Confiança }\end{array}$ & $\begin{array}{l}9 \\
7 \\
5 \\
5 \\
5\end{array}$ & $\begin{array}{l}3,33 \\
2,85 \\
3,20 \\
3,00 \\
2,80\end{array}$ \\
\hline
\end{tabular}

FIGURA 1: Quadro de quatro casas das evocações de pessoas idosas residentes em lares intergeracionais ao termo indutor família. Jequié-BA, 2013. 
ciedade $^{4}$, propicia os aportes afetivos necessários ao desenvolvimento de seus componentes, tornando-se um espaço indispensável para a sobrevivência e proteção das pessoas idosas e espaço privilegiado para o aprofundamento dos laços de solidariedade ${ }^{14}$.

As palavras união e companheirismo, também presentes no primeiro quadrante, apresentam núcleos de sentido que se relacionam com as evocações felicidade e respeito (primeira periferia) e paz, viver bem e harmonia (elementos de contraste) e reforçam a ideia de relações intergeracionais harmônicas e afetivas no núcleo familiar.

Destaca-se que as pessoas idosas que vivenciam aspectos positivos nas relações intergeracionais sentem-se mais positivas em relação a si próprias e ao seu mundo, suportando melhor as doenças, o stress e outras dificuldades ${ }^{15}$. No entanto, a convivência com duas, três ou mais gerações em uma mesma residência é cenário para conflitos nas relações intergeracionais devido às diferentes experiências culturais, comportamentais, de atitudes e valores entre as gerações ${ }^{16}$.

Nesse contexto, destaca-se que a convivência intergeracional conflituosa deve-se ao fato das gerações mais novas divergirem da geração dos idosos quanto às metas que devem ser atingidas, aos valores que devem ser respeitados e aos critérios para discernir o que deve ou não ser descartado ${ }^{17}$.

Desse modo, é importante ressaltar que embora as relações intergeracionais possam ser solidárias, porque proporcionam ajuda em certos momentos da vida, existe a necessidade de compreensão entre as gerações e isso deve ser praticado entre seus membros, para que se fomente a integração entre as diferentes idades e, consequentemente, se reduza o conflito dentro da família.

No quadrante superior direito do quadro de quatro casas localizam-se as palavras que tiveram uma alta frequência, mas cuja posição média na ordem de evocação não foi suficiente para que integrassem o núcleo central, constituindo assim, o que se tem denominado de elementos da primeira periferia. Nesse espaço da representação observa-se a presença dos termos cuidado, amor, felicidade, respeito e ajuda. Cabe assinalar que esta configuração positiva de família presente na primeira periferia, apresenta-se desdobrada na chamada segunda periferia (quadrante inferior direito).

Pode-se inferir que a evocação destes termos permeia e perpassa a compreensão dos papéis tradicionalmente atribuídos à família, como a proteção, cuidado, afeto e transmissão de valores morais, dentre eles o respeito ${ }^{18}$. Como mediadora entre o homem e a sociedade, a família constitui a unidade dinâmica das relações de cunho afetivo, social e cognitivo que estão imersas nas condições materiais, históricas e culturais de um dado grupo social ${ }^{19}$.
Dentre estes elementos da primeira periferia, destaca-se a palavra cuidado, que apresenta uma frequência superior a todas as palavras dos demais quadrantes. A família deve ser entendida como geradora de um sistema de cuidados próprio, que varia de acordo com sua cultura, na qual estão refletidos seus saberes sobre o que é saúde e desvio de saúde, impregnados de valores e crenças que se vão estruturando em seu cotidiano ${ }^{20}$.

$\mathrm{O}$ cuidado familiar caracteriza-se por ações e interações no sistema familiar direcionadas a cada um de seus membros para fortalecer a saúde e o bem-estar destes. Portanto, esse cuidado tem uma importância significante nas condições de saúde da família e, em especial, na família de pessoas idosas. Tais famílias tem assumido uma parcela cada vez maior de responsabilidade no cuidado domiciliar, visto que há um aumento significativo no número de doenças crônico-degenerativas acometendo pessoas idosas ${ }^{21}$.

As palavras cuidado e ajuda, podem estar refletindo que a coabitação dos idosos com os seus filhos e/ou netos contribui para a solidariedade intergeracional familiar que pode reverter-se na melhoria da qualidade de vida de idosos e demais gerações.

A este respeito, destaca-se que no Brasil, a família representa a principal fonte de cuidado para a população idosa. De fato, as famílias pobres com pessoas idosas formam arranjos com coabitação entre várias gerações, de modo a se auto ajudarem. As gerações mais jovens, muitas vezes desempregadas, usufruem da renda dos mais velhos, e estes dos cuidados que os mais jovens podem oferecer no espaço doméstico ${ }^{5,22}$.

A palavra amor também merece atenção dentre os elementos da primeira periferia, tendo a segunda maior frequência e sendo evocada mais prontamente. Esse termo revela que a família é entendida como um grupo de indivíduos que são vinculados por uma profunda ligação afetiva $^{23}$, espaço de vínculos afetivos profundos permeados por sentimento de amor. Enfatiza-se ainda, que o léxico amor revela que os idosos representam suas famílias como um celeiro em que ancoram as suas vidas, sendo expressão de apoio fundamental e de valorização da afetividade.

A evocação do termo felicidade relaciona a família à autopercepção de alegria e bem-estar para os idosos. Estudos envolvendo representações sobre velhice, cuidado e qualidade de vida mostraram que, para os idosos, é fundamental sentirem-se valorizados, recebendo ajuda e apoio afetivo por parte da família ${ }^{1,24}$.

Os elementos presentes no quadrante inferior direito, chamado de segunda periferia, são tidos como aqueles que possuem as menores frequências e as palavras menos importantes na ordem de evocação e, por esse motivo, podem ser considerados os elementos mais claramente periféricos ${ }^{10}$. Neste quadrante encontramse os termos apoio, dedicação, atenção, satisfação e confiança, que refletem atributos considerados como essenciais à dinâmica familiar. 
O termo apoio merece destaque, pois foi a palavra de maior frequência dentre os elementos da segunda periferia, sugerindo a família como uma importante fonte de apoio para os idosos. Destaca-se que este termo apresenta uma aproximação simbólica com a palavra ajuda, presente na primeira periferia. Sugere-se que o léxico ajuda remete ao provimento de necessidades materiais em geral, ajuda para trabalhos práticos e ajuda financeira. Já o léxico apoio, parece remeter, notadamente, ao apoio informativo, que compreende aconselhamento, sugestões e orientações, que podem ser usados para lidar com problemas e resolvê-los; e ao apoio denominado de interação social positiva, que está relacionado à disponibilidade de familiares para compartilhar atividades de lazer ou que ofereçam companhia no domicílio ${ }^{25}$.

Além deste elemento, destaca-se a presença dos léxicos atenção e dedicação, que sugerem que, para os idosos, estes são atributos indispensáveis nas relações familiares, possibilitando um viver harmônico ${ }^{26}$. Assim, as relações intergeracionais podem ser solidárias, proporcionando apoio, afeto e atenção em certos momentos vitais, quando há compreensão entre as gerações.

Os termos presentes no quadrante inferior esquerdo da Figura 1, elementos de contraste, são considerados os elementos de baixa frequência, porém, importantes para os sujeitos do estudo, uma vez que podem revelar elementos que reforçam as noções presentes no núcleo central ou na periferia ou a existência de um subgrupo minoritário portador de uma representação diferente ${ }^{4}$. Observam-se, nesse espaço da estrutura da representação, as palavras porto seguro, carinho, paz, viver bem, filhos, harmonia, proteção e benção divina.

As palavras situadas neste quadrante sustentam as representações presentes na primeira periferia e centram-se na percepção de família como um espaço indispensável para garantir o bem-estar, a sobrevivência e a proteção integral de seus membros.

Vale ainda ressaltar que a presença destes termos remete a uma representação de família como a base para a vida, uma instituição que proporciona paz e harmonia aos que dela partilham, denotando a profunda relação construída em torno desta. Atribui-se à família sentimentos positivos, como carinho, o que confere a esta o atributo de suporte nos momentos de dificuldade enfrentados e um porto seguro, termo mais evocado neste quadrante.

Complementar a essa visão, destaca-se a presença dos léxicos viver bem e proteção, considerados como atributos inerentes do sistema familiar ${ }^{27}$.

Entre os elementos deste quadrante, destaca-se também o termo benção divina que, apesar de sua baixa frequência, foi o mais prontamente evocado, o que expressa uma representação de família ancorada em algo divino, reforçando, provavelmente, a simbolização da família ao sagrado.

\section{Conclusão}

Através deste estudo, verificou-se que a estrutura representacional de pessoas idosas residentes em lares intergeracionais sobre família mostrou-se essencialmente positiva, representação esta que se apóia sobre valores hegemônicos presentes na sociedade associados à família, que permanece na realidade brasileira, como uma instituição essencial para a sobrevivência e cuidado às pessoas idosas.

Observou-se, portanto, uma representação que reproduz papéis tradicionalmente atribuídos à família, como o cuidado e o afeto. Por outro lado, cabe salientar que embora não tenha sido identificada pelos idosos, a corresidência pode ser marcada por relações intergeracionais conflituosas, devido às diferenças de valores sociais e culturais entre as gerações.

O conjunto dos sujeitos apresentou uma estrutura representacional que evidencia uma dimensão de completude e inteireza atribuída à família, ao mesmo tempo em que a revela como uma unidade essencial de cuidado aos idosos, capaz de promover apoios material, social e psicoafetivo. A família, para estes idosos, não é apenas uma importante fonte de apoio material, mas é representada, também, como fonte de satisfação e felicidade.

Apesar das mudanças ocorridas na constituição das famílias brasileiras advindas do processo de envelhecimento da população, ocasionando a conformação de um novo arranjo familiar, qual seja a corresidência, marcada pela convivência intergeracional, o estudo demonstra a existência de significativas permanências simbólicas sobre a família. Essas permanências nas representações sociais mostram a família como base de uma estrutura, porto seguro, provedora de cuidado e de amor, revelando uma forte carga afetiva dos idosos no tocante à família.

\section{REFERÊNCIAS}

1.Comerlato EMB, Guimarães I, Alves ED. Tempo de plantar e tempo de colher: as representações sociais de profissionais de saúde e idosos sobre o processo de envelhecimento. Rev eletr enferm. 2007; 9:736-47.

2.World Health Organization. Envelhecimento ativo: uma política de saúde. Tradução de Suzana Gontijo. Brasília (DF): OPAS; 2005.

3.Instituto Brasileiro de Geografia e Estatística. Ministério do Planejamento, Orçamento e Gestão. Sinopse do Censo Demográfico 2010. Rio de Janeiro: IBGE; 2010. 4.Souza RFS, Skubs T, Brêtas ACP. Envelhecimento e família: uma nova perspectiva para o cuidado de enfermagem. Rev Bras Enferm. 2007; 60: 263-7.

5.Camarano AA, Kanso S, Mello JL, Pasinato MT. Famílias: espaço de compartilhamento de recursos e vulnerabilidades. In: Camarano AA, organizadora. Os novos idosos brasileiros muito além dos 60 ? Rio de Janeiro: IPEA; 2004. p. 137-67. 
6.Abric JC. A abordagem estrutural das representações sociais. In: Moreira ASP, Oliveira DC, organizadoras. Estudos interdisciplinares de representação social. Goiânia (GO): AB Editora; 2000. p. 27-38.

7.Abric JC. A zona muda das representações sociais. In: Oliveira DC, organizadora. Representações sociais: uma teoria sem fronteiras. Rio de Janeiro: Museu da República; 2005. p. 23-34.

8.Sá CP. Núcleo central das representações sociais. Petrópolis (RJ): Vozes; 1996.

9.Ministério da Saúde $(\mathrm{Br})$. Secretaria de Atenção à Saúde. Departamento de Atenção Básica. Caderno de Atenção Básica no 19 - Envelhecimento e saúde da pessoa idosa. Brasília (DF): Ministério da Saúde; 2007.

10.Oliveira DC, Marques SC, Gomes AMT, Teixeira MCTV. Análise das evocações livres: uma técnica de análise estrutural das representações sociais. In: Moreira ASP, Camargo BV, Jesuino JC, Nóbrega SM, organizadores. Perspectivas teórico-metodológicas em representações sociais. João Pessoa (PB): Ed. Universitária da UFPB; 2005.p. 573-602.

11.Gomes AMT, Oliveira DC. A estrutura representacional de enfermeiros acerca da enfermagem: novos momentos e antigos desafios. Rev enferm UERJ. 2007; 15: 168-75.

12.Vergès P. Approche du no yau central: proprieties quantitatives et structurales. In: Guimelli C. Structures et transformations des representations sociales. Lausanne: Delachauxet Niestlé; 1994. p. 233-54.

13.Abric JC. Méthodes d'études des représentations sociales. Ramonville Saint-Agne (Fr): Edition Éres; 2003. 14.Marcon SS, Lopes MCL, Fernandes J, Antunes CRM, Waidman MAP. Famílias cuidadoras de pessoas com dependência: um estudo bibliográfico. Online Braz J Nurs. 2006; 5(1).

15.França LHFP, Silva AMTB, Barreto MSL. Programas intergeracionais: quão relevantes eles podem ser para a sociedade brasileira? Rev bras geriatr gerontol. 2010; 13: 519-32.

16.Camarano AA, Kanso S; Mello JL. Como vive o idoso brasileiro? In: Camarano AA, organizadora. Os novos idosos brasileiros muito além dos 60? Rio de Janeiro: IPEA; 2004. p.25-73.

17.Petrini JC. Mudanças sociais e mudanças familiares. In: Petrini JC; Cavalcante VRS, organizadores. Família, sociedade e subjetividade: uma perspectiva multidisciplinar. Petrópolis (RJ): Vozes; 2005.p.29-54.

18.Zamberlan MAT, Camargo F, Biasoli-Alves ZMM. Interações na família: revisões empíricas. In: Zamberlan MAT, Biasoli-Alves ZMM. Interações familiares: teoria, pesquisa e subsídios à intervenção. Londrina (PR): UEL; 1997. p. 39-57.

19.Dessen MA, Polonia AC. A família e a escola como contextos de desenvolvimento humano. Paidéia. 2007; 17: 21-32. 20.Cattani RB, Girardon-Perlini NMO. Cuidar da pessoa idosa doente no domicílio na voz de cuidadores familiares. Rev eletr enferm. 2004; 6: 254-71.

21.Marcon SS, Radovanovic CAT, Waidman MAP, Oliveira MLF, Sales CA. Vivência e reflexões de um grupo de estudos junto às famílias que enfrentam a situação crônica de saúde. Texto \& contexto enferm. 2005; 14: 116-24.

22. Teixeira SM, Rodrigues VS. Modelos de família entre idosos: famílias restritas ou extensas. Rev bras geriatr gerontol. 2009; 12: 239-54.

23.Alarcão M.(Des) Equilíbrios familiares. Coimbra (Pt): Quateto; 2006.

24.Silva MG, Boemer MR. The experience of aging: a phenomenological perspective. Rev Latino-Am Enfermagem. 2009; 17: 380-6.

25.Rosa TGC. Redes de apoio social: In: Litvoc J, Brito FC. Envelhecimento: prevenção e promoção da saúde. São Paulo: Ateneu; 2004.

26.Goldani, AM. Contratos intergeracionais e reconstrução do estado de bem estar. Porque se deve repensar essa relação para o Brasil? In: Camarano AA, organizadora. Os novos idosos brasileiros muito além dos 60? Rio de Janeiro: IPEA; 2004.p.211-39.

27.Elsen I. Desafios da enfermagem no cuidado à saúde. In: Bub LIR, coordenador. Marcos para a prática de enfermagem com famílias. Florianópolis (SC): Editora da UFSC; 1994. p. 61-77. 